\title{
Hyperbaric oxygen and hyperbaric air treatment result in comparable neuronal death reduction and improved behavioral outcome after transient forebrain ischemia in the gerbil
}

\author{
Michal Malek • Malgorzata Duszczyk • \\ Marcin Zyszkowski • Apolonia Ziembowicz • \\ Elzbieta Salinska
}

Received: 23 July 2012/ Accepted: 19 September 2012/Published online: 2 October 2012

(C) The Author(s) 2012. This article is published with open access at Springerlink.com

\begin{abstract}
Anoxic brain injury resulting from cardiac arrest is responsible for approximately two-thirds of deaths. Recent evidence suggests that increased oxygen delivered to the brain after cardiac arrest may be an important factor in preventing neuronal damage, resulting in an interest in hyperbaric oxygen (HBO) therapy. Interestingly, increased oxygen supply may be also reached by application of normobaric oxygen (NBO) or hyperbaric air (HBA). However, previous research also showed that the beneficial effect of hyperbaric treatment may not directly result from increased oxygen supply, leading to the conclusion that the mechanism of hyperbaric prevention of brain damage is not well understood. The aim of our study was to compare the effects of HBO, HBA and NBO treatment on gerbil brain condition after transient forebrain ischemia, serving as a model of cardiac arrest. Thereby, we investigated the effects of repetitive $\mathrm{HBO}, \mathrm{HBA}$ and $\mathrm{NBO}$ treatment on hippocampal CA1 neuronal survival, brain temperature and gerbils behavior (the nest building), depending on the time of initiation of the therapy (1, 3 and $6 \mathrm{~h}$ after ischemia). HBO and HBA applied 1,3 and $6 \mathrm{~h}$ after ischemia significantly increased neuronal survival and behavioral performance and abolished the ischemia-evoked brain temperature increase. NBO treatment was most effective when applied $1 \mathrm{~h}$ after ischemia; later application had a weak or no protective effect. The results show that HBO and HBA applied between
\end{abstract}

M. Malek · M. Duszczyk - A. Ziembowicz · E. Salinska $(\bowtie)$ Department of Neurochemistry, Mossakowski Medical Research Centre, Polish Academy of Sciences, 5 Pawinskiego Str.,

02-106 Warsaw, Poland

e-mail: elas@cmdik.pan.pl

M. Zyszkowski

Department of Anesthesiology and Intensive Care,

Military Institute of Medicine, Warsaw, Poland
1 and $6 \mathrm{~h}$ after ischemia prevent ischemia-evoked neuronal damage, which may be due to the inhibition of brain temperature increase, as a result of the applied rise in ambient pressure, and just not due to the oxygen per se. This perspective is supported by the finding that NBO treatment was less effective than HBO or HBA therapy. The results presented in this paper may pave the way for future experimental studies dealing with pressure and temperature regulation.

Keywords Ischemia - Hyperbaric oxygen therapy . Hyperbaric air - Neuronal damage - Brain temperature . Gerbil

\section{Introduction}

Sudden cardiac arrest is a common manifestation of cardiovascular disease affecting a large number of people, and despite advances in resuscitation techniques, the percentage of surviving patients is still very low (Nolan et al. 2008). The mortality in patients who achieve return of spontaneous circulation (ROSC) is due largely to postcardiac arrest syndrome which comprises anoxic brain injury, post-cardiac arrest myocardial dysfunction, ischemia/reperfusion response and persistent precipitating pathology (Nolan et al. 2008). Among these anoxic brain injury is a major cause of mortality, responsible for approximately two-thirds of deaths. The mechanisms of brain tissue damage triggered by cardiac arrest and resuscitation include energy deficit, anoxic depolarization, excitotoxicity, disturbed calcium homeostasis, formation of free radicals and activation of cell death signaling pathways (Busl and Greer 2010). Currently, hypothermia is the only proven treatment for anoxic brain injury after cardiac arrest, and although some drugs appear to have short-term 
benefits, no specific drug therapy has been confirmed to improve long-term survival in randomized controlled trials (Morley 2011; Deakin et al. 2010).

There is a lot of recent evidence that hyperbaric oxygen (HBO) prevents neuronal damage and improves neurological outcome after cardiac arrest or stroke (for review see Harch and Neubauer 2009), and there is the opinion that amount of oxygen delivered to the brain in a short time after cardiac arrest or after stroke may be an important factor in preventing neuronal damage resulted from brain ischemia (Neumar 2011; Rosenthal et al. 2003; Van Meter et al. 2008). The neurological outcome after cardiac arrest may be greatly affected by the oxygen inhaled immediately after resuscitation, and there is a growing body of evidence suggesting that delivering too much oxygen too quickly may increase injury associated with postischemic reperfusion. There are reports that postresuscitation hyperoxemia $\left(\mathrm{PaO}_{2} \geq 300 \mathrm{mmHg}\right)$ exposure in the first $60 \mathrm{~min}$ after ROSC increased the mortality in patients and was associated with lower independent functional status among patients who survived (Kilgannon et al. 2011).

Despite many reports on beneficial results of $\mathrm{HBO}$ in global cerebral ischemia/anoxia in animal models and human clinical studies (for review see Harch and Neubauer 2009), this therapy did not find the common use in neurological diseases treatment. Pressure-related complications of HBO and growing concern that HBO treatment may generate toxic free radicals, resulted in skepticism about the safety and efficacy of HBO in cerebral ischemia (Kot and Mathieu 2011). Nevertheless, HBO still remains the subject of interest of many scientists: moreover, the critical analysis of negative results and data from new animal studies renewed the interest in HBO therapy (Michalski et al. 2011). Recent publications have provided essential information about the important factors influencing HBO efficacy such as the therapeutic time window and the mechanism of action (Rockswold et al. 2010; Lou et al. 2004). It is now known that HBO not only significantly increases oxygen pressure and concentration in the arteries, resulting in better oxygen supply to the ischemic areas, but also increases cerebral blood flow (CBF) into the injured brain, the so-called inverse steal phenomenon mediated by nitric oxide (NO) (Lassen and Palvölgyi 1968; Atochin et al. 2003; Dean et al. 2003). HBO also ameliorates blood flow velocity due to increased deformability of red blood cells (van Hulst et al. 2003).

There is now increasing experimental evidence that HBO can afford neuroprotection after experimental global cerebral ischemia induced by vascular occlusion. It has been shown that HBO treatment results in the reduction in neuronal death and accelerated neurological recovery in different animal models of global ischemia (Iwatsuki et al.
1994; Kapp et al. 1982; Krakovsky et al. 1998; Takahashi et al. 1992) and also in an experimental cardiac arrest model in dogs (Rosenthal et al. 2003). In addition, HBO improves also the rate of return of spontaneous circulation after prolonged cardiopulmonary arrest (Van Meter et al. 2008), decreases lactate concentration in cerebrospinal fluid, improves mitochondrial function after focal cerebral ischemia (Rockswold et al. 2001; Daugherty et al. 2004), triggers multiple neuroprotective effects such as reduction in concentration of cyclooxygenase-2 (COX-2) (Yin et al. 2002) and intracellular adhesion molecule-1 (ICAM-1) (Buras et al. 2000), and decreases the expression of proapoptotic genes including hypoxia inducible factor- $1 \alpha$ (HIF$1 \alpha$ ), p53, caspase-9 and caspase-3 (Li et al. 2005). It was also shown that HBO may cause hypothermia due to increased oxygen partial pressure (Fenton et al. 1993).

Regardless of these beneficial effects of HBO on brain tissue, the consequences of forced oxygen application on other organs have to be considered. Lung toxicity is a known phenomenon following exposure to a high oxygen concentration. Prolonged exposure to hyperoxia resulting from $\mathrm{HBO}$ and from normobaric oxygen (NBO) can damage pulmonary epithelial cells, and concomitantly occurring chronic pulmonary diseases are additional contraindications in the use of oxygen in cerebral ischemia ( $\mathrm{Li}$ et al. 2007; Sinclair et al. 2004).

The application of increased oxygen to ischemic areas dates from the mid-1900s and in the early experiments compressed air was used in hyperbaric medicine (for review see Singhal 2006), and later on Smith et al. (1961) and Illingworth (1962) showed the beneficial effect of HBO on cerebral ischemia. To date there is little data showing the effect of hyperbaric air (HBA) on postischemic survival. HBA is not used even as a control to compare the effects of HBO. The few papers containing data about the effects of HBA treatment on brain tissue concern the hypoxic tolerance induced by hyperbaric preconditioning or the impact on cell viability of hypoxic brain slices (Peng et al. 2008; Günther et al. 2004). Recent publications showing that the beneficial effect of HBO may not be the only result of increased oxygen supply (Rosenthal et al. 2003; Miljkovic-Lolic et al. 2003) suggest that the mechanisms of hyperbaric prevention of brain damage still remain unclear.

The aim of our study was to compare the effects of HBO, HBA and NBO treatment on gerbil brain condition after transient forebrain ischemia as a model of cardiac arrest, by testing neuronal survival in the hippocampus, changes in the brain temperature and also basic behavior in the nest-building test. Additionally, possible differences dependent on the time of initiation of the hyperbaric therapy were investigated. 


\section{Experimental procedures}

\section{Animals}

All the experiments used male Mongolian gerbils (Meriones unguiculatus), bred in the Animal Colony of the Medical Research Centre, Polish Academy of Sciences in Warsaw, aged 12-13 weeks and weighing about $60 \mathrm{~g}$. The animals were kept at the room temperature $\left(24-25^{\circ} \mathrm{C}\right)$, fed ad libitum and randomly assigned into experimental groups (group 1-sham operated, group 2-non treated ischemia, group 3-ischemia $+\mathrm{HBO}$, group 4-ischemia + HBA and group 5-ischemia + NBO). The animals from groups 2-5 were submitted to a 3-min forebrain ischemia, followed by either hyperbaric therapy or normobaric oxygen application, started at three different times after ischemia (Fig. 1). Sham-operated animals served as controls in evaluation of neuronal cell loss and in behavioral experiments. Animals used in nest-building test experiments served also for neuronal loss evaluation. The number of animals per experimental group ranged from $n=5$ to $n=9$ (exact number given in figure legends). The total number of animals used in this study $n=120$. All animal experiments were carried out according to the Polish and European Community Council regulations concerning experiments on animals.

The animal experiments were approved by the Local Ethical Committee in Warsaw, Poland, and performed in accordance with Polish governmental regulations (Dz.U.97.111.724) and the European Community Council Directive of 24 November 1986 (86/609/EEC). All efforts were made to minimize animal suffering and the number of animals used.

\section{Forebrain ischemia}

The brain ischemia was performed as described earlier (Chandler et al. 1985; Duszczyk et al. 2006b). Briefly, the

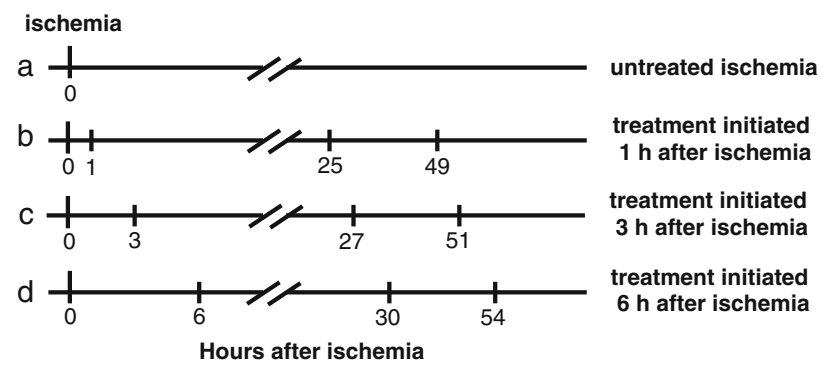

Fig. 1 Scheme of the procedure of experiments including untreated 3-min ischemia (a) and HBO, HBA or NBO treatment initiated at different times after ischemia $(\mathbf{b}, \mathbf{c}, \mathbf{d})$. Each time point indicates initiation of the treatment lasting $60 \mathrm{~min}$; treatments were repeated in 24-h intervals (for details of the protocol see section "Experimental procedures") animals were anesthetized with $4 \%$ halothane in a gas mixture containing $30 \% \mathrm{O}_{2}$ and $70 \% \mathrm{~N}_{2} \mathrm{O}$, and 2 min before the operation, the concentration of halothane was reduced to $2 \%$ and kept at this concentration during ischemia. The carotid arteries were isolated through an anterior middle cervical incision, made after the injection of local anesthetics. Cerebral ischemia was induced by the occlusion of both common carotid arteries with miniature aneurismal clips for $3 \mathrm{~min}$. Sham-operated animals were exposed to similar surgery without carotid artery occlusion. During the surgery, animals were kept on the heating pad at $37{ }^{\circ} \mathrm{C}$. After wound closure animals were put into separate cages and moved to the room designed for behavioral test or brain temperature measurements accordingly. Both groups of animals were then submitted to hyperbaric therapy or normobaric oxygen. In this study, ischemic protocol resulted in less than $3 \%$ mortality and there was no mortality that could be associated with hyperbaric or normobaric oxygen treatment.

\section{Hyperbaric treatment}

Animals subjected to ischemia were divided into three groups. Animals from group 3 were treated with HBO therapy (compression in $100 \%$ oxygen), group 4 was compressed in atmospheric air (HBA) and group 5 consisted of animals treated with normobaric oxygen (100\% oxygen at 1 ATA). As a control served sham-operated animals treated with HBO. Animals were placed into the hyperbaric chambers (for HBO-Model B-11 Animal Research Chamber, Reimers Systems, INC., USA; for HBA-Hyperbaric Chamber, Technika Podwodna, Poland) for $60 \mathrm{~min} 1,3$ or $6 \mathrm{~h}$ after ischemia and compressed to 2.5 ATA (rate of compression and decompression 1 ATA/ min). Animals from the NBO group were placed in an unpressurized hyperbaric chamber with a constant $100 \%$ oxygen flow through the chamber at a rate of $0.51 / \mathrm{min}$. The treatment was repeated for 3 following days. The temperature in the hyperbaric chambers was monitored during the whole session and was maintained at $24-25{ }^{\circ} \mathrm{C}$.

\section{Measurement of brain temperature}

For continuous recording and analysis of the brain temperature in conscious and freely moving gerbils, a telemetric system to measure the brain temperature was utilized (Mini Mitter VitalView hardware and software system, Mini Mitter Co. Inc. Oregon, USA). The temperature was measured in gerbils submitted to 3-min forebrain ischemia and treated with $\mathrm{HBO}, \mathrm{NBO}$ and HBA. The procedure for the brain temperature probe (probe type Mini Mitter XM-FH-BP) implantation has previously been described in detail (Duszczyk et al. 2006a). Briefly, the 
holders of the brain temperature probes were implanted unilaterally in gerbils submitted to halothane anesthesia and the tips into the striatum, approximately to the same depth as the hippocampus. Two days later, the probes were inserted into the probe holders and the gerbils were placed in plastic cages resting on the telemetry receiver. Temperature measurements began $3 \mathrm{~h}$ before an ischemic episode and continued for $72 \mathrm{~h}$. The temperature signals from the probe were sampled every $30 \mathrm{~s}$, to ensure strict control of the temperature. The mean temperatures were calculated for individual time points (usually every $1 \mathrm{~h}$ ). Because of technical limitations, brain temperature was not measured during hyperbaric sessions (around $60 \mathrm{~min}$ ) and the measurements were continued immediately after returning the animals from hyperbaric chamber into the cages. It was shown earlier that insertion of small temperature probe into brain caused only minor injury that did not affect the main results (Duszczyk et al. 2006a; Nurse and Corbett 1994; Zhang et al. 1997).

\section{Histochemistry}

One week (for TUNEL staining) or 2 weeks (for cresyl violet staining) after ischemia, animals were killed for brain examination (3-5 from each experimental group). This time was chosen according to earlier observations that after transient forebrain ischemia, most of the apoptotic processes in gerbil brain is finished, whereas one week after ischemia apoptosis is still observed (Ko et al. 2009; Goda et al. 2012). Animals were anesthetized with halothane and subjected to intracranial perfusion fixation with $4 \%$ neutralized formalin (Sigma-Aldrich, St. Louis, Missouri, USA). The brains were removed and immersed in $4 \%$ formalin for 1 week, then transferred to absolute ethanol and embedded in paraffin. Ten- $\mu \mathrm{m}$ cross sections from the dorsal part of the hippocampus (between 2.2 and $3.5 \mathrm{~mm}$ posterior to bregma) were used to evaluate the brain damage size and hippocampal apoptotic neurons. Sections were stained with cresyl violet (Sigma, St. Louis, Missouri, USA) or terminal deoxynucleotidyl transferasemediated dUTP-nick end labeling (TUNEL, In Situ Cell Death Detection Kit, Fluorescein; Roche, Switzerland). For each animal, at least 5 sections of the central part of CA1 region in both hippocampi were analyzed for neuron density or TUNEL stained cells (number of animals per group $n=3-5)$. The number of neurons was counted in central CA1 area of $0.5 \mathrm{~mm}$ length using AxioVison imaging program (Carl Zeiss, Aalen, Germany). A mean number of neurons stained with cresyl violet were expressed as a percentage of mean number of neurons of sham-operated gerbils. The mean number of pyramidal neurons in CA1 region of sham-operated gerbils amounts to 155 per $0.5 \mathrm{~mm}$.
Nest-building test

Nest-building behavior was evaluated in gerbils submitted to 3-min forebrain ischemia (group 2) and those treated after ischemia with HBO, HBA and NBO (group 3, 4 and 5 , respectively) starting at different times after operation (1, 3 and $6 \mathrm{~h})$. Additional groups consisted of sham-operated gerbils (group 1) exposed to HBO, HBA and NBO at the same times as the ischemic groups.

After surgery, each animal was placed into a cage covered with a paper towel and the nest building was assessed each day for 7 days following the ischemic episode. Paper shredding was scored on a 4-point scale adapted from Babcock et al. (1993): $0=$ none; $1=$ pieces $>4 \mathrm{~cm}^{2} ; 2=$ pieces between 2 and $4 \mathrm{~cm}^{2} ; 3=$ pieces $<2 \mathrm{~cm}^{2}$ (Duszczyk et al. 2006a). Some of these animals were subsequently used for evaluation of neuronal damage.

Statistical analysis

Apart from nest-building scores, the results are expressed as mean \pm SEM for each experimental group. Statistical analysis of that data was performed by one way ANOVA, with further analysis using the post hoc least significance test for significant differences between groups (GraphPad Prism, version 5.01; GraphPad Software Inc., La Jolla, California, USA). Differences were considered significant with $\mathrm{p}$ value less than 0.05 .

The nest-building scores are presented as medians, estimated by calculation of the interquartile range (IQR) and tested by two-way analysis of variance (ANOVA).

\section{Results}

$\mathrm{HBO}$ and HBA prevent neurodegeneration

The counting of pyramidal neurons in CA1 area of hippocampus showed that 3 -min ischemia resulted in a significant, $82 \%$ neuronal loss in comparison with control, shamoperated animals $\left(F_{1,15}=135, p<0.001\right)$ (Fig. 2). Ischemia-initiated apoptotic processes and one week after ischemic insult 45 TUNEL-positive cells in examined CA1 area (0.5 mm length) were observed (Fig. 3). The application of HBO treatment $1 \mathrm{~h}$ after ischemia increased the number of neurons observed in this region to $54 \%$ of control (significant difference from ischemia, $F_{1,26}=21.19, p<0.001$ ) (Fig. 2). Application of HBO 3 or $6 \mathrm{~h}$ after ischemia resulted in significant increase in number of neurons to $41 \%$ in both cases $\left(F_{1,14}=92.2, \quad p<0.001\right.$ and $F_{1,14}=60.38$, $p<0.001$, respectively). HBO also significantly reduced the number of TUNEL-positive cells observed in CA1 by 80,62 

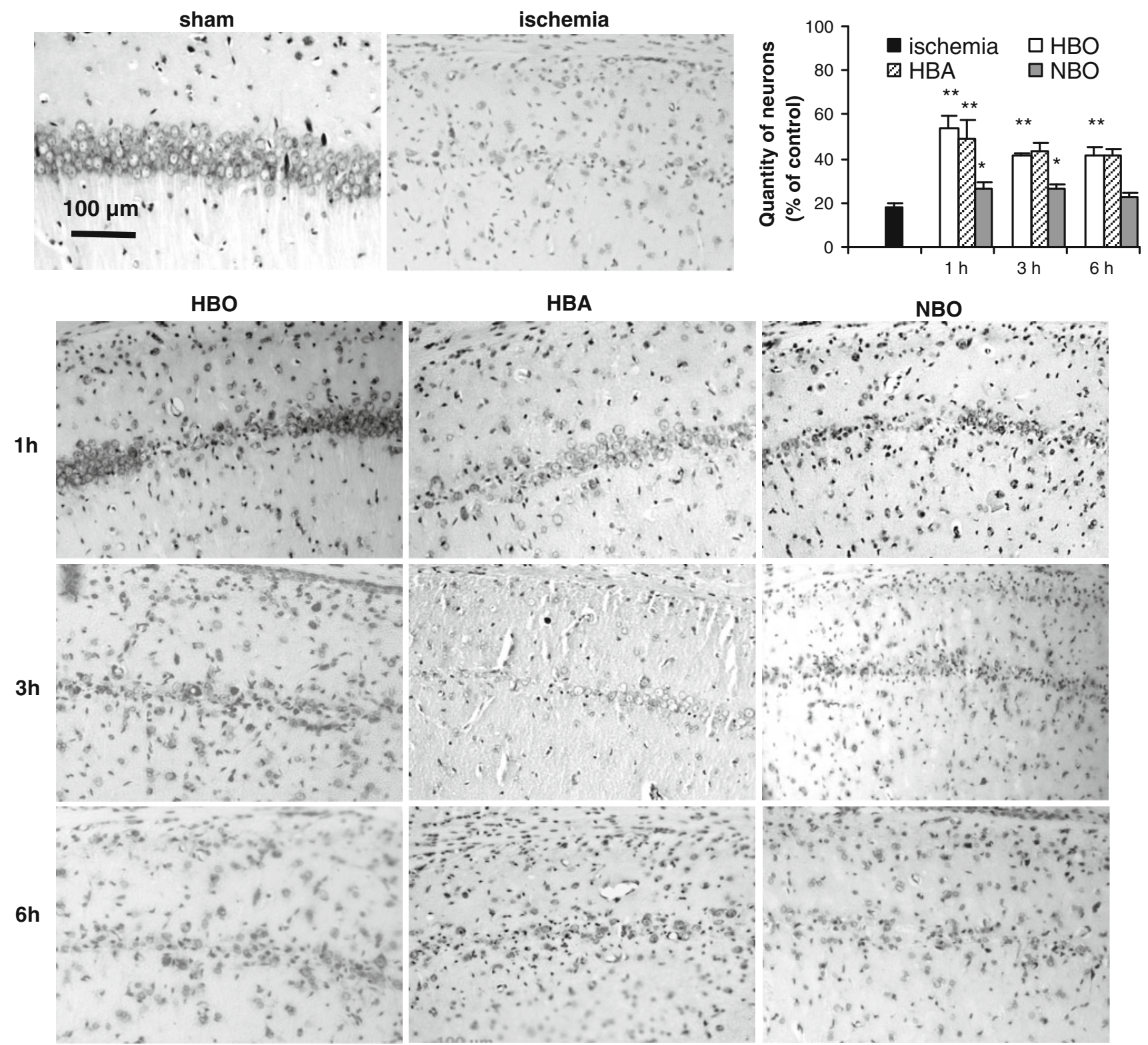

Fig. 2 The effect of $\mathrm{HBO}, \mathrm{HBA}$ and $\mathrm{NBO}$ treatment initiated at different times after ischemia $(1,3$ and $6 \mathrm{~h})$ on number of neurons in hippocampal CA1 region of the gerbil brain, stained with cresyl violet. The hyperbaric and NBO treatment was applied 3 times in 24-h intervals. Brain tissue was examined 14 days after ischemia. Top

and $49 \%$, respectively, to the time of treatment initiation $\left(F_{3,13}=25.1, p<0.001\right)$ (Fig. 3$)$ The use of HBA also significantly increased the number of neurons (Fig. 2). Application of HBA $1 \mathrm{~h}$ after ischemia resulted in an increase in viable neurons to $49 \% \quad\left(F_{1.12}=29.24\right.$, $p<0.001$ ), and HBA therapy applied 3 or $6 \mathrm{~h}$ after ischemia in 43 and $41 \%$ of control, respectively $\left(F_{1,12}=45\right.$, $p<0.001$ and $\left.F_{1,15}=71.1, p<0.001\right)$. In comparison with untreated ischemia, HBA treatment decreased the number of TUNEL-positive cells by $67 \%$ when initiated $1 \mathrm{~h}$ after right corner graph represents results expressed as percentage of surviving neurons compared to the mean control level of $290 \mathrm{cell} / \mathrm{mm}$ in central CA1 region in sham-operated animals. Number of analyzed animals per group $n=5$. Results on the graph are mean values \pm SEM; $* p<0.05, * * p<0.001$

ischemia and by 58 and $40 \%$ when initiated 3 and $6 \mathrm{~h}$ after ischemia, respectively $\left(F_{3,10}=13.2, p<0.001\right)$. Statistical analysis of results comparing HBO and HBA therapy did not reveal significant differences between their effectiveness. The application of NBO 1 and $3 \mathrm{~h}$ after ischemia resulted in only a slight increase in the number of surviving neurons (29 and $26 \%$ in both times, respectively, compared to $18 \%$ of surviving neurons in non-treated ischemia; $F_{1,14}=7.63$, $p<0.05$ and $F_{1,27}=9.28, p<0.01$, respectively), which was significantly lower compared to $\mathrm{HBO}$ and HBA 
sham

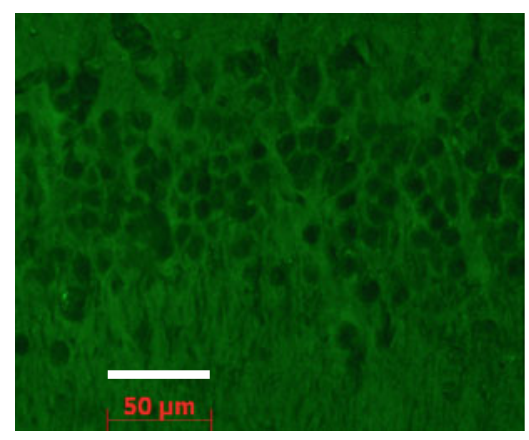

HBO

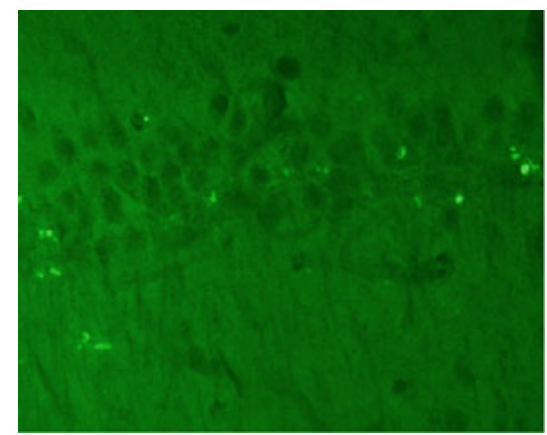

$3 \mathbf{h}$

$6 \mathrm{~h}$
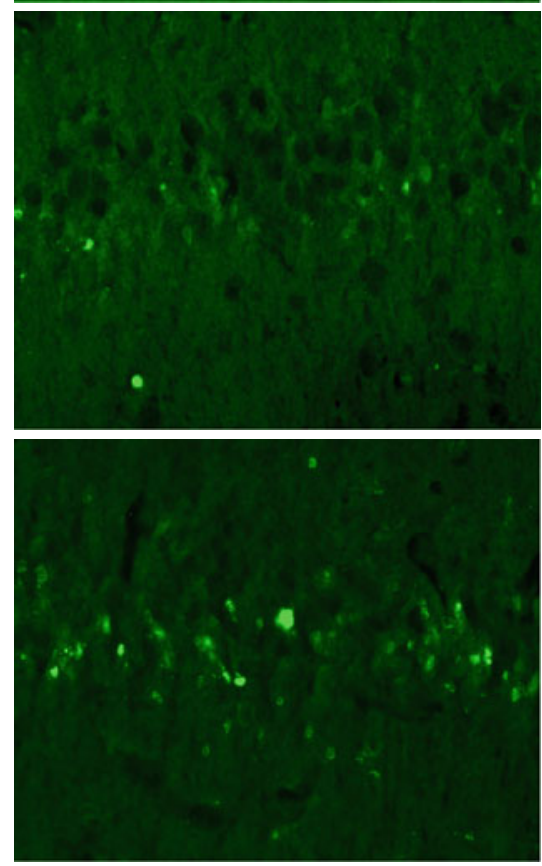

Fig. 3 TUNEL-positive cells detected in CA1 region in HBO, HBA and NBO treated animals. Treatment was initiated at different times after ischemia (1, 3 and $6 \mathrm{~h}$ ). The hyperbaric and NBO treatment was applied 3 times in 24-h intervals. Brain tissue was examined 7 days after ischemia. Top right corner graph represents results expressed as

$\left(F_{2,34}=5.9, \quad p<0.01\right.$ and $F_{2, \quad 25}=11.6, \quad p<0.001$, respectively). NBO applied $1 \mathrm{~h}$ after ischemia reduced the TUNEL-positive cells number by $70 \%$ and by $42 \%$ when initiated $3 \mathrm{~h}$ after ischemic insult $\left(F_{1,8}=39.9, p<0.001\right.$ ischemia

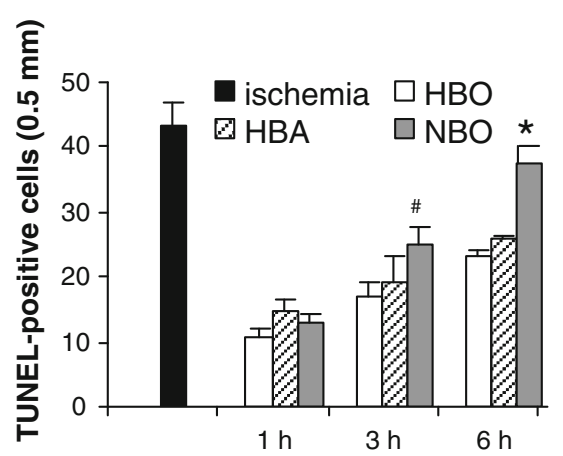

HBA

NBO

number of TUNEL-positive cells in the central CA1 area of $0.5 \mathrm{~mm}$ length. Number of analyzed animals per group $n=3-4$. Results on the graph are mean values \pm SEM. *-significantly different from HBO and HBA groups, $p<0.001$; \#-significantly different from HBO group, $p<0.01$

and $F_{1,8}=11.6, p<0.01$, respectively). The application of $\mathrm{NBO}$ at $6 \mathrm{~h}$ resulted neither in significant increase in number of neurons observed in CA1 region of hippocampus nor in decrease in TUNEL-positive cells (Figs. 2, 3). 
The effect of HBO and HBA on gerbil brain temperature

Brain temperature measurements showed that the mean temperature of gerbil brain after implantation of the probe varied between 36.5 and $37^{\circ} \mathrm{C}$. A significant increase, up to $37.8^{\circ} \mathrm{C}$, in brain temperature was observed up to $4 \mathrm{~h}$ after ischemia which remained through the whole measurement period. The application of HBO therapy 1 or $3 \mathrm{~h}$ after ischemic incident resulted in a significant decrease in brain temperature $\left(F_{1,14}=5.03, \quad p<0.04 \quad\right.$ and $F_{1,20}=17.9, p<0.001$, respectively) and was observed up to $10 \mathrm{~h}$ after HBO treatment; subsequently, the temperature remained in the range registered before ischemia (Fig. 4a, b). HBO applied $6 \mathrm{~h}$ after ischemia also prevented brain temperature increase $\left(F_{1,20}=22.16, p<0.001\right)$ (Fig. 4c). The application of HBA to the ischemic gerbils 1 or $3 \mathrm{~h}$ after ischemia also resulted in a significant decrease in the brain temperature $\left(F_{1,20}=19.5, p<0.001\right.$ and $F_{1,18}=7.56, p<0.05$, respectively) and was observed for up to $10 \mathrm{~h}$ after the first HBA treatment (Fig. 4a, b); conversely, the application of HBA $6 \mathrm{~h}$ after ischemic incident resulted in only a slight, insignificant decrease in brain temperature and was only observed up to $3 \mathrm{~h}$ after treatment (Fig. 4c). Hyperbaric sessions themselves had an influence on the temperature of the brain, and after each session an additional, significant transient drop of temperature was observed.

NBO treatment to ischemic gerbils resulted in a significant decrease in brain temperature only when NBO was applied $1 \mathrm{~h}$ after ischemia and measured temperatures were significantly different from the ischemic control only up to $3 \mathrm{~h}$ after NBO $(p<0.01)$. Application of NBO 3 and $6 \mathrm{~h}$ after ischemia produced a short transient decrease which disappeared when NBO treatment was terminated (Fig. 4).

The effect of HBO and HBA on nest-building behavior in ischemic gerbils

The nest-building behavior of gerbils was monitored for 7 days following the ischemic insult. Our current and previous experiments showed that naïve and sham-operated animals start nest building immediately after placing them into the experimental cage (Duszczyk et al. 2006a), and after 3-min ischemia, the gerbils exhibited a 2-day delay in the initiation of nest building and a paper shredding score of 3 was reached at the end of the observation period (day 6 or 7) (Fig. 5). In the present experiment, sham-operated animals were treated with HBO and HBA, which did not significantly influence the nest-building behavior. In all experimental groups, the nest-building process improved over time but significant differences in the time required to reach the highest score were observed.
The HBO therapy in gerbils submitted to 3-min ischemia resulted in significant improvement in the nest-building scores. The animals which received the HBO therapy 1 or $3 \mathrm{~h}$ after the insult started to build the nest within $24 \mathrm{~h}$ after ischemia, and the nest-building process was significantly improved compared to non-treated animals $(F=22.28, \quad p<0.001$ for $\mathrm{HBO}$ and $F=22.02$, $p<0.001$ ) (Fig. 4a, b). The delay of nest building in animals treated with HBO $6 \mathrm{~h}$ after ischemia was only 1 day, but the difference in behavior of treated and non-treated animals was significant $(F=18.65, p<0.001)$ (Fig. 5c). Animals treated with HBA also showed significant improvement in nest-building behavior compared to nontreated $(F=18.43, p<0.001$ for HBA treatment started $1 \mathrm{~h}$ after insult, $F=21.57, p<0.001$ and $F=21.32$, $p<0.001$ for treatment initiated 3 and $6 \mathrm{~h}$ after ischemia, respectively), and this was not significantly different from that observed after HBO. NBO treatment initiated 1 and $6 \mathrm{~h}$ after ischemia also resulted in quicker nest building $(F=27.40, p<0.001$ and $F=33.07, p<0.001$, respectively) (Fig. 5a, c), although the NBO treatment applied $3 \mathrm{~h}$ after ischemia did not.

\section{Discussion}

The results presented in this paper demonstrate that both HBO and HBA, applied up to $6 \mathrm{~h}$ after transient forebrain ischemia in gerbils, induce morphological protection of the CA1 pyramidal neurons and also reduce behavioral deficits in the nest-building task to a higher degree than the application of NBO.

The CA1 pyramidal neurons both in experimental animals and in humans undergo selective cell death after transient forebrain ischemia (Bonnekoh et al. 1990). This phenomenon is termed "delayed neuronal death" because pyramidal neurons of CA1 mostly remain unchanged at the early stage after the event but begin to die in a time window of usually 3-4 days after ischemia due to apoptotic processes (Nitatori et al. 1995). As known from experimental research, the CA1 pyramidal neurons of the gerbil hippocampus degenerate within 2-4 days after 5-min transient global ischemia and it was reported that only $5.8 \%$ of the neurons survive 3 weeks later (Bonnekoh et al. 1990). Our results show that one week after an ischemic insult, lasting 3-min apoptotic processes were still in progress, and after 2 weeks, only $18 \%$ of CA1 pyramidal neurons were intact. HBO therapy significantly reduced the number of dying neurons, and protection was most effective when $\mathrm{HBO}$ was initiated $1 \mathrm{~h}$ after ischemia; however, the therapeutic window for HBO was still open $6 \mathrm{~h}$ after ischemia. These results are in agreement with previously published data reporting a therapeutic window 
Fig. 4 Effect of HBO, HBA and NBO treatment started $1 \mathrm{~h}$ (a), $3 \mathrm{~h} \mathrm{(b)}$ and $6 \mathrm{~h} \mathrm{(c)} \mathrm{after}$ ischemia on gerbil brain temperature. The hyperbaric and NBO treatment was applied 3 times in 24-h intervals. Main graphs show temperature measurement during first $27 \mathrm{~h}$. Brain temperature was measured for $74 \mathrm{~h}$; complex results are presented on small graphs. Three-min ischemia was induced at 4th hour after probe implantation (arrow). Results are mean values \pm SEM; $n=4-5$ per each group. *-HBO group significantly different from untreated ischemia, $p<0.01$; \#_HBA group significantly different from untreated ischemia, $p<0.01$
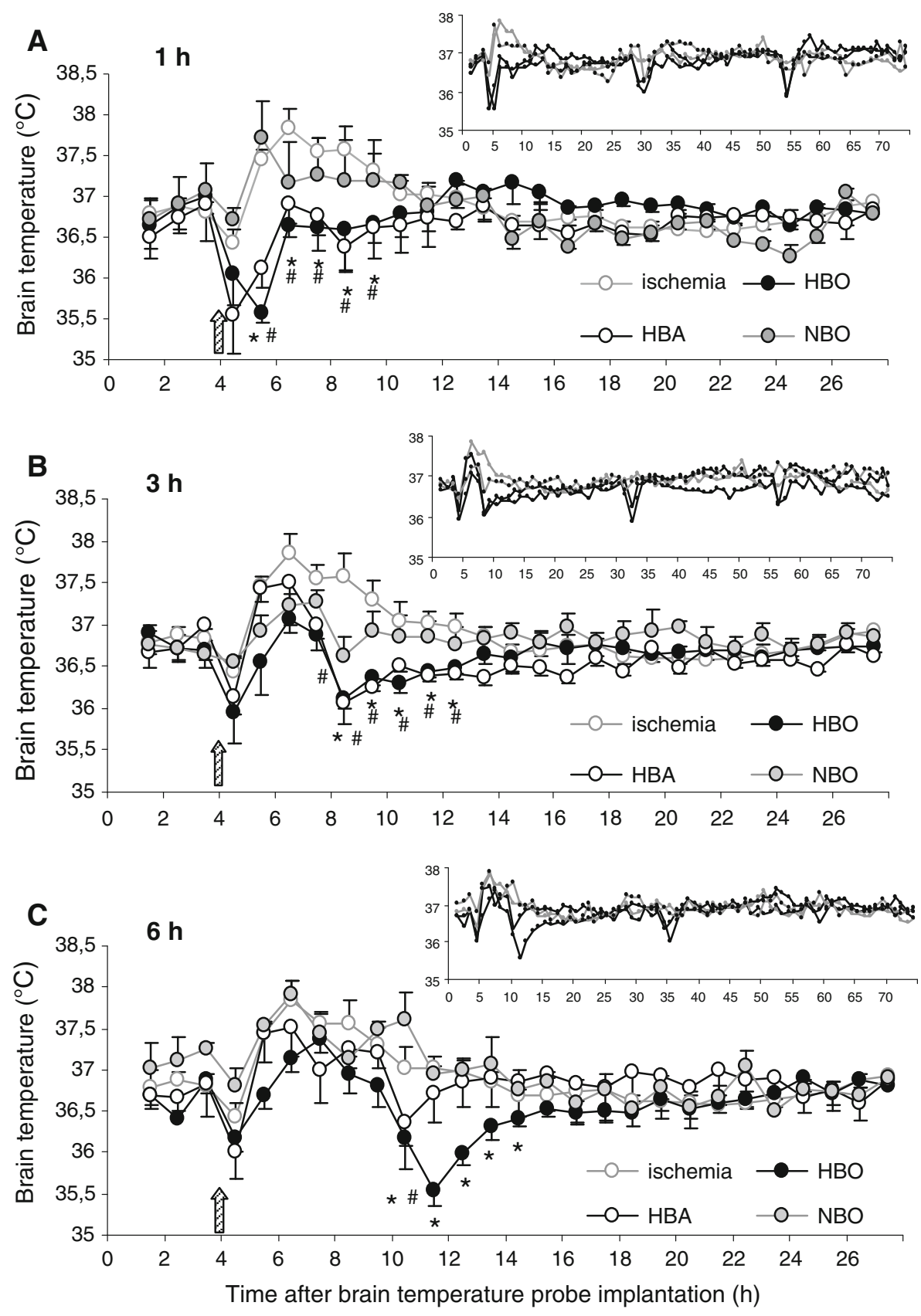

for HBO (from 1.5 to 3 ATA) using different animal models of both global and focal ischemia, where neuronal protection effect was observed even when this therapy was applied up to $12 \mathrm{~h}$ after ischemic insult (Li et al. 2005; Lou et al. 2004; Niklas et al. 2004; Wang et al. 2008; Zhang et al. 2005).

There are reports that normobaric hyperoxia administered early in the injury and for a prolonged period of time prevents delayed post-ischemic neuronal death (Kumaria and Tolias 2009). NBO applied during ischemia had been shown to significantly reduce neuronal cell death, and brain infarct volume both in vivo and in vitro inhibits the upregulation of matrix metalloproteinase-2 and attenuate nitric oxide production (Yuan et al. 2010; Kim et al. 2005; Günther et al. 2004). Studies using NBO and HBO after experimental cerebral ischemia provide evidence for blood-brain barrier stabilization, although the effect of NBO was rather weak (Veltkamp et al. 2005). Our results show that NBO applied after ischemia resulted in only a slight reduction in apoptosis and increase in the number of surviving neurons.

The results presented in this paper indicate a more potent protective effect of $\mathrm{HBO}$ than NBO and are in agreement with data published by Beynon et al. (2007) 
Fig. 5 Nest-building behavior in gerbils after $\mathrm{HBO}, \mathrm{HBA}$ and NBO treatment started at $1 \mathrm{~h}$ (a), $3 \mathrm{~h} \mathrm{(b)}$ and $6 \mathrm{~h} \mathrm{(c)} \mathrm{after}$ ischemia. The hyperbaric and NBO treatment was applied 3 times in 24-h intervals. Nest building was assessed each day for 7 days following ischemic episode. Values are median nest-building score, IQR for each data point $\leq 1$. Group size: sham $n=5$; ischemia $n=9$; $\mathrm{HBO}, \mathrm{HBA}$ and NBO each time group $n=5$
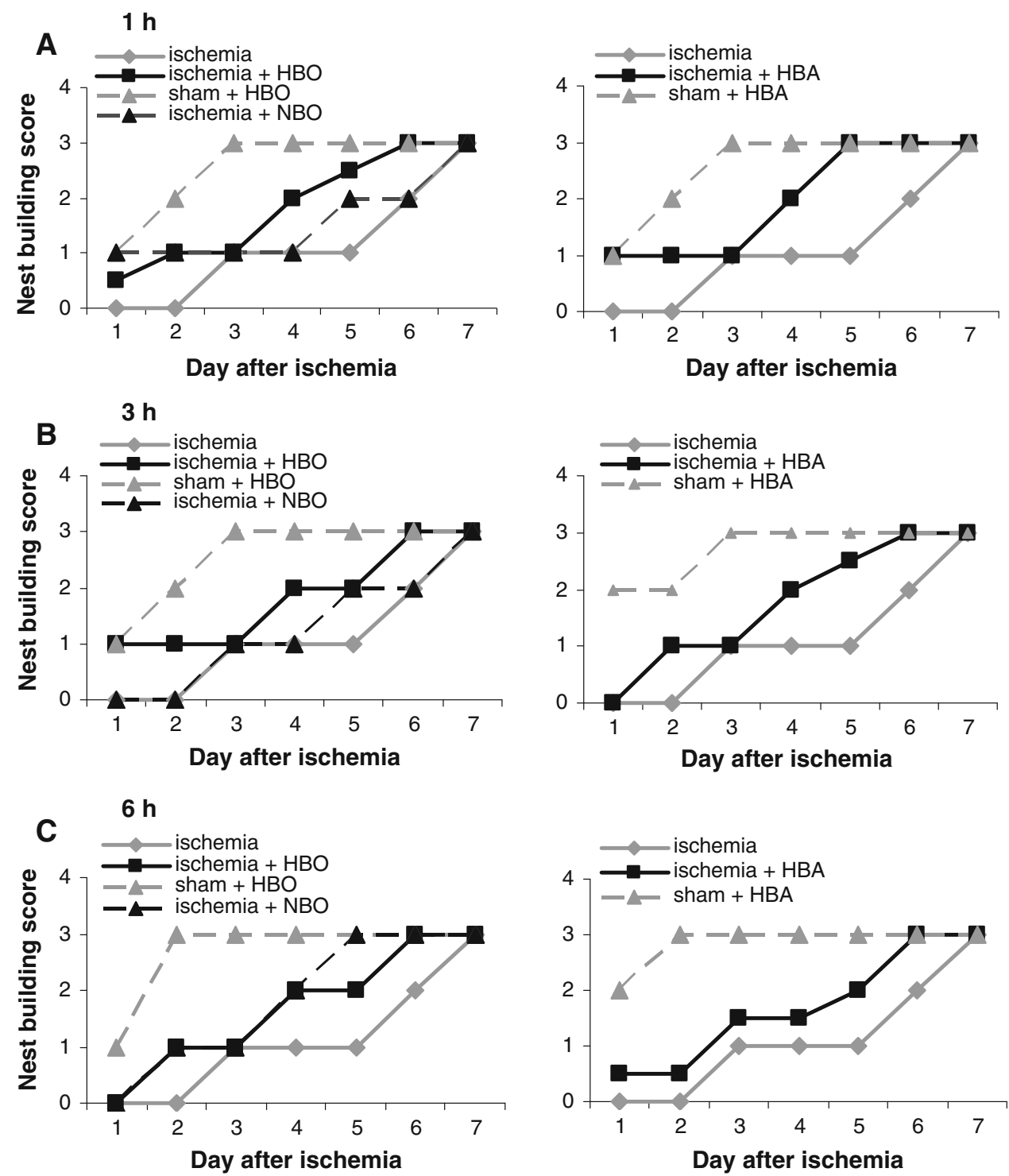

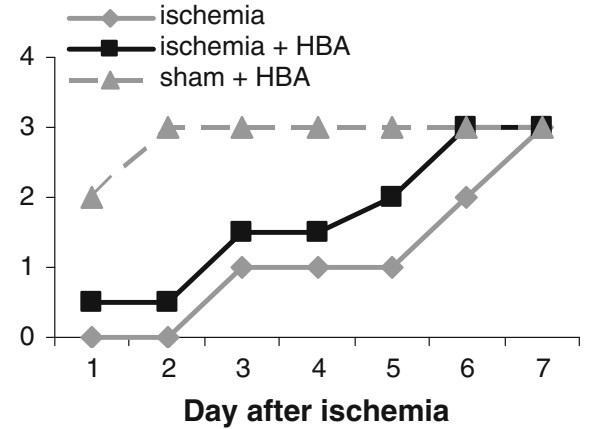

showing that even delayed HBO treatment is more effective than early prolonged NBO. Surprisingly, in our experiments, HBA therapy appeared to be more effective than NBO. HBA applied up to $6 \mathrm{~h}$ after ischemia resulted in decrease in apoptotic neurons and significant increase in the number of surviving neurons in the CA1 region of the gerbil hippocampus. Only few studies describe the effect of HBA on postischemic survival, and published data show only a slight, if any, protective effect of HBA (Peng et al. 2008; Günther et al. 2004). This makes the results presented in this paper more interesting, since the beneficial effect of HBA was not only limited to a reduced number of dying neurons but also manifested itself in the animals' behavior. These results may also resolve doubts concerning the effectiveness of oxygen administration by aviators mask in air pressurized chambers (Harch and Neubauer 2009).
Although the neuronal death after ischemic episode is delayed, during the initial postischemic period preceding the death of CA1 neurons, gerbils demonstrate a behavioral deficit, which seems to be linked to hippocampal dysfunction (Duszczyk et al. 2006a). The control gerbils exhibit stereotypical nest-building behavior, characterized by a species-specific shredding of the nest material, in this case a soft paper towel. It is well documented that global brain ischemia in gerbils results in disturbances in nestbuilding behavior, and this correlates directly with the extent of ischemic morphological damage (Antonawich et al. 1997; Baldwin et al. 1993; Duszczyk et al. 2006a). A typical male gerbil builds a nest within 12-24 h. In our studies, sham-operated animals serving as controls started nest building immediately after placing them in the experimental cage. Animals submitted to 3-min ischemia showed a 2-day delay in the initiation of nest building. It 
has been suggested that disruption of nest building is not a secondary effect of increased motor activity, which usually accompanies transient global ischemia, but results from delays in habituation and spatial mapping resulting from hippocampal damage (Antonawich et al. 1997; Babcock et al. 1993). Administration of $\mathrm{HBO}$ treatment after ischemia significantly improved nest building, which may reflect a protective effect of hyperoxygenation on neurons. Animals which received NBO and HBA treatment after ischemia also showed an improvement in nest-building behavior, which was not significantly different from that observed after HBO. Generally, delivery of oxygen under increased partial pressure within $6 \mathrm{~h}$ after ischemia significantly improved animal's nest-building behavior. The beneficial effect of HBO on neurological deficits graded on the Garcia scale (Garcia et al. 1995) was reported earlier in the rat model of focal cerebral ischemia (Miljkovic-Lolic et al. 2003; Beynon et al. 2007); however, no beneficial effect of NBO was observed (Beynon et al. 2007) and, to our knowledge, there are no reports regarding the effect of HBA on animal behavior after ischemia. Thus, results presented in this paper for the first time show that HBA may not only protect CA1 neurons from ischemia-induced damage but also improve nest-building behavior in gerbils. These results indicate that the increased survival of neurons observed in our experiments correlates with an improved neurological outcome.

There are many mechanisms proposed to explain the beneficial effects of HBO treatments, including increased oxygenation of ischemic and penumbra area in the brain, reduction in blood-brain barrier damage, elevation of autophagic activity, attenuation of nitric oxide production and inhibition of apoptotic protein expression (Ostrowski et al. 2005; Yuan et al. 2010; Veltkamp et al. 2005; Yan et al. 2011). There are reports that supplemental oxygenation applied during reperfusion may result in intensification of injury (Rink et al. 2010). However, increased oxygenation evoked by HBO reduces neuronal death and improves neurological outcome, which was shown not only in our experiments but also after canine cardiac arrest (Rosenthal et al. 2003), circulatory occlusion in cats (Kapp et al. 1982) and cardiopulmonary arrest in pigs (Van Meter et al. 2008). It was recently shown that the improvement in neurological function and reduced neuronal cell death observed after cardiac arrest and reperfusion does not result from increased cerebral oxygen delivery or oxygen consumption (Rosenthal et al. 2003). It is possible that hyperbaric oxygen or hyperbaric treatment itself may trigger more protective mechanisms and the maintenance of brain temperature might be one of them.

Previous studies show that hyperthermia is frequently observed in the first $72 \mathrm{~h}$ after resuscitation from cardiac arrest and were associated with poor outcome (Takasu et al. 2001). Similarly, ischemic stroke is usually followed by hyperthermia, resulting from both a stroke-induced inflammatory reaction and disturbances in cell metabolism (Zaremba 2004). Mild therapeutic hypothermia is currently the only therapy that improved survival and brain function after initial resuscitation from cardiac arrest (Janata and Holzer 2009; Sugerman and Abella 2009). It protects the brain after ischemia by decreasing metabolism, inhibiting excitatory amino acid release, and also by attenuation of reactive oxygen species formation and the immune response during reperfusion (Janata and Holzer 2009).

Mongolian gerbils are particularly susceptible to bilateral carotid occlusion, which results in global forebrain ischemia, due to the incomplete circle of Willis (Du et al. 2011). In this model of ischemia, brain temperature often significantly decreases during occlusion but then quickly returns to normal after the onset of recirculation (Zhang et al. 1997; Colbourne et al. 1993). However, at 10-20 min after the start of recirculation, brain temperature increases by $0.7-1{ }^{\circ} \mathrm{C}$ and this postischemic hyperthermia is observed for 45-90 min.; thereafter, temperature returns to normal. Brain temperature measurements presented in this paper are mostly in agreement with previous observations. However, in our experiments, the increase in brain temperature lasted for almost $6 \mathrm{~h}$ after reperfusion and remained slightly increased to the end of measurements. Previously, we also observed a prolonged (3-4 h) period of post-ischemic hyperthermia in gerbils submitted to 3-min global ischemia (Duszczyk et al. 2005, 2006a). The basis of postischemic temperature increase in the gerbil remains uncertain; however, the hyperthermia described in certain focal ischemia models in rats has been suggested to be caused by altered blood flow in the hypothalamus (He et al. 1999; Zhao et al. 1994), although damage of the bloodbrain barrier and development of inflammatory processes may also be an explanation (Veltkamp et al. 2005).

Wood and Gonzales (1996) showed that hyperthermia increases the imbalance between energy supply and demand following ischemia. Temperature-dependent changes in functional neurological outcome, histopathology, intraneuronal calcium accumulation and the levels of enzymes mediating calcium effects, including neuronal excitability, synaptic modulation and release of excitatory neurotransmitters, were demonstrated in number of animal models of cardiac arrest and stroke (Dietrich et al. 1996; Ginsberg and Busto 1998; Wass et al. 1995; Coimbra et al. 1996). These changes may cause further development of postischemic injury of neurons, leading to irreversible lesions. Hyperthermia may also induce additional dysfunction of the blood-brain barrier, facilitating the regional influx of leukocytes as a result of the ischemia-evoked 
inflammatory reaction (Zaremba 2004). Thus, the prevention of hyperthermia within the first hours after resuscitation from cardiac arrest or stroke is important for preventing further damage to the brain.

The results presented in this paper show that both HBO and HBA treatment applied up to $3 \mathrm{~h}$ after ischemia prevents ischemia-evoked increase in brain temperature, especially that observed up to $10 \mathrm{~h}$ after reperfusion. Within $72 \mathrm{~h}$, brain temperature of animals treated with hyperbaric therapy remained slightly lower or the same level as before ischemia. Hyperbaric treatment applied $6 \mathrm{~h}$ after ischemic insult also prevented the increase in brain temperature, although HBA was less effective than HBO. NBO treatment effectively prevented brain temperature increase only when applied $1 \mathrm{~h}$ after ischemia. The results presented in this paper show the correlation between morphological protection, behavioral improvement and attenuation of postischemic hyperthermia. This suggests the causal connection between presented data and indicates a possible key role of brain temperature decrease in beneficial effects of hyperbaric treatments.

It is known from the literature that increased partial pressure of oxygen causes hypothermia. It has been shown in rats that $\mathrm{HBO}$ is associated with a significant decrease in body temperature and that this effect is evoked mostly by an increase in the partial pressure of oxygen, and only in small part by heat loss due to pressure alone (Fenton et al. 1993). In our experiments, a decrease in brain temperature during both HBO and HBA was also observed, while only a slight temperature drop was observed in gerbils subjected to NBO. This observation is difficult to explain because the oxygen partial pressure during NBO is two times higher than during HBA (data not shown); however, perhaps the effect of pressurization itself should not be totally excluded. In fact, Fenton et al. (1993) observed a decrease in body temperature in pressure control experiments, where the partial pressure of oxygen at 4 ATA was the same as the partial pressure in air at 1 ATA. Recently, Tsai et al. (2005) found beneficial effects of $8 \%$ oxygen pressurized to $253 \mathrm{kPa}$ (2.5 ATA) in resuscitating rats with experimental heatstroke. The mechanism of this hyperbaric treatment induced hypothermia is still not clear, although the initially proposed involvement of 5- $\mathrm{HT}_{1 \mathrm{~A}}$ receptors was excluded (Fenton et al. 1993). These results together with results presented in this paper suggest that the pressurization itself (occurring during $\mathrm{HBO}$ and HBA) might be the causal reason for the observed beneficial effects of $\mathrm{HBO}$ and HBA.

Concerning the potential mechanisms of pressure-related hypothermia, the suggestion that decrease in $\mathrm{CBF}$ caused by high pressure may induce hypothermia and also does not seem to be good explanation because pressure used in presented in this paper experiments (2.5 ATA) only slightly changes CBF (Demechenko et al. 2005). Further, one of the explanations of observed hypothermia may be the increased oxygen supply delivered to the ischemic and penumbra regions of the brain and in consequence improvement in aerobic metabolism of injured regions, at the time window which may guarantee at least partial prevention of neuronal damage (Rockswold et al. 2001). However, Rosenthal et al. (2003) using the animal cardiac arrest model showed no increase in cerebral oxygen delivery and consumption during hyperbaric treatment. It was suggested that probably there is no ongoing ischemia during postischemic hypoperfusion and that energy metabolism may not be limited by oxygen delivery but rather by the activity of aerobic metabolic enzymes (McKinley et al. 1996; Rosenthal et al. 2003).

Hyperbaric reduction in blood-brain barrier damage preventing inflammatory processes and inhibition of neutrophil adhesion to the endothelium are also factors which may contribute in neuronal protection (Buras and Reenstra 2007; Veltkamp et al. 2005). There is now agreement that the best time window for hyperbaric therapy is within the first $6 \mathrm{~h}$ after ischemic insult. Our results show that this time window is effective both for HBO and HBA. The best time for NBO application is up to $3 \mathrm{~h}$ after ischemia, and during this time, NBO may serve as a useful adjunct therapy widening the time window for reperfusion by as much as $2 \mathrm{~h}$ (Kim et al. 2005). However, clinical practice shows that oxygen applied less than $1 \mathrm{~h}$ after resuscitation from cardiac arrest results in a dose-dependent association between supranormal oxygen tension and risk of in-hospital death (Kilgannon et al. 2011).

In conclusion, the results presented here show for the first time that not only $\mathrm{HBO}$ but also HBA applied between 1 and $6 \mathrm{~h}$ after transient forebrain ischemia may prevent ischemia-induced neuronal damage in the CA1 region of the gerbil brain and that this protection is protection is mostly likely due to a pressure-related inhibition of brain temperature increase which typically originates from ischemia. Although early applied NBO also resulted in neuronal protection, this treatment was less effective than delayed HBO or HBA therapy.

Acknowledgments This study was supported by Polish Ministry of Sciences and Higher Education grant no. N N401 003935. We would like to thank Technika Podwodna for making accessible the hyperbaric chamber used in HBA experiments. We are also grateful to Prof. Jerzy Lazarewicz from Medical Research Centre and Dr Jacek Kot from National Center for Hyperbaric Medicine in Gdynia for reading the manuscript and useful comments.

Open Access This article is distributed under the terms of the Creative Commons Attribution License which permits any use, distribution, and reproduction in any medium, provided the original author(s) and the source are credited. 


\section{References}

Antonawich FJ, Melton CS, Wu P, Davis JN (1997) Nesting and shredding behavior as an indicator of hippocampal ischemic damage. Brain Res 764:249-252

Atochin DN, Demechenko IT, Astern J, Boso AE, Piantadosi CA, Huang PL (2003) Contributions of endothelial and neuronal nitric oxide synthase to cerebrovascular responses to hyperoxia. J Cereb Blood Flow Metab 23:1219-1226

Babcock A, Baker D, Lovec R (1993) Locomotor activity in the ischemic gerbil. Brain Res 625:351-354

Baldwin HA, Jones JA, Cross AJ, Green AR (1993) Histological, biochemical and behavioural evidence for the neuroprotective action of chlormetazole following prolonged carotid occlusion. Neurodegeneration 2:139-146

Beynon C, Sun L, Marti HH, Heiland S, Veltkamp R (2007) Delayed hyperbaric oxygenation is more effective than prolonged normobaric hyperoxia in experimental focal cerebral ischemia. Neurosci Lett 425:141-145

Bonnekoh P, Barbier A, Oschlies U, Hossmann K-A (1990) Selective vulnerability in the gerbil hippocampus: morphological changes after 5-min ischemia and long survival times. Acta Neuropathol 80:18-25

Buras JA, Reenstra WR (2007) Endothelial-neutrophil interactions during ischemia and reperfusion injury: basic mechanisms of hyperbaric oxygen. Neurol Res 29:127-131

Buras JA, Stahl GL, Svoboda KK, Reenstra WR (2000) Hyperbaric oxygen downregulates ICAM-1 expression induced by hypoxia and hypoglycemia: the role of NOS. Am J Physiol Cell Physiol 278:C292-C302

Busl KM, Greer DM (2010) Hypoxic-ischemic brain injury: pathophysiology, neuropathology and mechanisms. NeuroRehabilitation 26:5-13

Chandler MJ, DeLeo JA, Carney JM (1985) An unanesthetized gerbil model of cerebral ischemia-induced behavioral changes. J Pharmacol Methods 14:137-146

Coimbra C, Drake M, Moller FB, Wieloch T (1996) Long-lasting neuroprotective effect of postischemic hypothermia and treatment with an anti-inflammatory/antipyretic drug. Stroke 27:1578-1585

Colbourne F, Nurse SM, Corbett D (1993) Temperature changes associated with forebrain ischemia in the gerbil. Brain Res 602:264-267

Daugherty WP, Levasseur JE, Sun D, Rockswold GL, Bullock MR (2004) Effects of hyperbaric oxygen therapy on cerebral oxygenation and mitochondrial function following moderate lateral fluid-percussion injury in rats. J Neurosurg 101:499-504

Deakin CD, Morrison LJ, Morley PT, Callaway CW, Kerber RE, Kronick SL, Lavonas EJ, Link MS, Neumar RW, Otto CW, Parr M, Shuster M, Sunde K, Peberdy MA, Tang W, Hoek TL, Böttiger BW, Drajer S, Lim SH, Nolan JP, Advanced Life Support Chapter Collaborators (2010) Part 8: advanced life support: 2010 international consensus on cardiopulmonary resuscitation and emergency cardiovascular care science with treatment recommendations. Resuscitation 81(Suppl 1):e93-e174

Dean JB, Mulkey DK, Garcia AJ 3rd, Putnam RW, Jenderson RA 3rd (2003) Neuronal sensitivity to hyperoxia, hypercapnia, and inert gases at hyperbaric pressures. J Appl Physiol 95:883-909

Demechenko IT, Luchakov YI, Moskvin AN, Gutsaeva DR, Allen BW, Thalmann ED, Piantadosi CA (2005) Cerebral blood flow and brain oxygenation in rats breathing oxygen under pressure. J Cereb Blood Flow Metab 25:1288-1300

Dietrich WD, Busto R, Globus MY, Ginsberg MD (1996) Brain damage and temperature: cellular and molecular mechanisms. Adv Neurol 71:177-194
Du XY, Zhu XD, Dong G, Lu J, Wang Y, Zeng L, Zhao TY, Ye HH, Li RS, Bai JY, Chen ZW (2011) Characteristics of circle of Willis variations in the Mongolian gerbil and newly established ischemia-prone gerbil group. ILAR e-J 52:e1-e7

Duszczyk M, Gadamski R, Ziembowicz A, Danysz W, Lazarewicz JW (2005) NMDA receptor antagonism does not inhibit induction of ischemic tolerance in gerbil brain in vivo. Neurotox Res 7(4):283-292

Duszczyk M, Ziembowicz A, Gadamski R, Lazarewicz JW (2006a) Behavioral evaluation of ischemic damage to CA1 hippocampal neurons: effects of preconditioning. Acta Neurobiol Exp 66:311-319

Duszczyk M, Gadamski R, Ziembowicz A, Lazarewicz JW (2006b) Antagonists of group I metabotropic glutamate receptors do not inhibit induction of ischemic tolerance in gerbil hippocampus. Neurochem Int 48:478-484

Fenton LH, Beck G, Djali S, Robinson MB (1993) Hypothermia induced by hyperbaric oxygen is not blocked by serotonin antagonists. Pharmacol Biochem Behav 44:357-364

Garcia JH, Wagner S, Liu K-F, Hu X-J (1995) Neurological deficit and extent of neural necrosis attributable to middle cerebral artery occlusion in rats. Stroke 26:627-635

Ginsberg MD, Busto R (1998) Combating hyperthermia in acute stroke: a significant clinical concern. Stroke 29:529-534

Goda W, Satoh K, Nakashima M, Hara A, Niwa M (2012) PBN fails to suppress in delayed neuronal death of hippocampal CA1 injury following transient forebrain ischemia in gerbils. Neurosci Lett 517:47-51

Günther A, Manaenk A, Franke H, Wagner A, Schneider D, Berrouschot J, Reinhardt R (2004) Hyperbaric and normobaric reoxygenation of hypoxic rat brain slices-impact on purine nucleotide and cell viability. Neurochem Int 45:1125-1132

Harch PG, Neubauer RA (2009) HBO therapy in global cerebral ischemia/anoxia and coma. In: Jain KK (ed) Textbook of hyperbaric medicine, 5th edn. Hogrefe \& Huber Publishers, Göttingen, pp 235-274

He Z, Yamawaki T, Yang S, Day AL, Simpkins JW, Naritomi H (1999) Experimental model of small deep infarcts involving the hypothalamus in rats: changes in body temperature and postural reflex. Stroke 30:2743-2751

Illingworth C (1962) Treatment of arterial occlusion under oxygen at two atmospheres pressure. Br Med J 5315:1271-1275

Iwatsuki N, Takahashi M, Ono K, Tajima T (1994) Hyperbaric oxygen combined with nicardipine administration accelerates neurologic recovery after cerebral ischemia in canine model. Crit Care Med 22:858-863

Janata A, Holzer M (2009) Hypothermia after cardiac arrest. Prog Cardiovasc Dis 52:168-179

Kapp JP, Phillips M, Markov A, Smith RR (1982) Hyperbaric oxygen after circulatory arrest: modification of postischemic encephalopathy. Neurosurgery 11:496-499

Kilgannon JH, Jones AE, Parrillo JE, Dellinger RP, Milcarek B, Hunter K, Shapiro NI, Trzeciak S, Emergency Medicine Shock Research Network (EMShockNet) Investigators, (2011) Relationship between supranormal oxygen tension and outcome after resuscitation from cardiac arrest. Circulation 123:27172722

Kim HY, Singhal AB, Lo EH (2005) Normobaric hyperoxia extends the reperfusion window in focal cerebral ischemia. Ann Neurol 57:571-575

Ko IG, Shin MS, Kim BK, Kim SE, Sung YH, Kim TS, Shin MC, Cho HJ, Kim SC, Kim SH, Kim KH, Shin DH, Kim CJ (2009) Tadalafil improves short-term memory by suppressing ischemiainduced apoptosis of hippocampal neuronal cells in gerbils. Pharmacol Biochem Behav 91:629-635 
Kot J, Mathieu D (2011) Controversial issues in hyperbaric oxygen therapy: a European Committee for Hyperbaric Medicine Workshop. Diving Hyperb Med 41:101-104

Krakovsky M, Rogatsky G, Zarchin N, Mayevsky A (1998) Effect of hyperbaric oxygen therapy on survival after global cerebral ischemia in rats. Surg Neurol 49:412-416

Kumaria A, Tolias CM (2009) Normobaric hyperoxia therapy for traumatic brain injury and stroke: a review. Br J Neurosurg 23:576-584

Lassen NA, Palvölgyi R (1968) Cerebral steal during hypercapnia and the inverse reaction during hypocapnia observed by the 133 xenon technique in man. Scand J Clin Lab Invest Suppl 102:XIII

Li Y, Zhou C, Calvert JW, Colohan ART, Zhang JH (2005) Multiple effects of hyperbaric oxygen on the expression of HIF- $1 \alpha$ and apoptotic genes in global ischemia-hypotension rat model. Exp Neurol 191:198-210

Li LF, Liao SK, Ko YS, Lee CH, Quinn DA (2007) Hyperoxia increases ventilation-induced lung injury via mitogen-activated protein kinases: a prospective, controlled animal experiment. Crit Care 11(1):R25

Lou M, Eschenfelder CC, Herdegen T, Brecht S, Deuschl G (2004) Therapeutic window for use of hyperbaric oxygenation in focal transient ischemia in rats. Stroke 35:578-583

McKinley BA, Morris WP, Parmley CL, Butler BD (1996) Brain parenchyma $\mathrm{P}_{\mathrm{O} 2}, \mathrm{P}_{\mathrm{CO} 2}$ and $\mathrm{pH}$ during and after hypoxic, ischemic brain insult in dogs. Crit Care Med 24:1858-1868

Michalski D, Härtig W, Schneider D, Hobohm C (2011) Use of normobaric and hyperbaric oxygen in acute focal cerebral ischemia - a preclinical and clinical review. Acta Neurol Scand 123:85-97

Miljkovic-Lolic M, Silbergleit R, Fiskum G, Rosenthal RE (2003) Neuroprotective effects of hyperbaric oxygen treatment in experimental focal cerebral ischemia are associated with reduced brain leukocyte myeloperoxidase activity. Brain Res 971:90-94

Morley PT (2011) Drugs during cardiopulmonary resuscitation. Curr Opin Crit Care 17:214-218

Neumar RW (2011) Optimal oxygenation during and after cardiopulmonary resuscitation. Curr Opin Crit Care 17:236-240

Niklas A, Brock D, Schober R, Schultz A, Schneider D (2004) Continuous measurement of cerebral tissue oxygen pressure during hyperbaric oxygenation-HBO effects on brain edema and necrosis after severe brain trauma in rabbits. Neurol Sci 219:77-82

Nitatori T, Sato N, Waguri S, Karasawa Y, Araki H, Shibanai K, Kominami E, Uchiyama Y (1995) Delayed neuronal death in the CA1 pyramidal cell layer of the gerbil hippocampus following transient ischemia is apoptosis. J Neurosci 15(2):1001-1011

Nolan JP, Neumar RW, Adrie C, Aibiki M, Berg RA, Böttinger BW, Callaway C, Clark RSB, Geocadin RG, Jauch EC, Kern KB, Laurent I, Longstreth WT, Merchant RM, Morley P, Morrison LJ, Nadkarni V, Peberdy MA, Rivers EP, Rodriguez-Nunez A, Sellke FW, Spaulding C, Sunde K, Hoek TV (2008) Post-cardiac arrest syndrome: epidemiology, pathophysiology, treatment, and prognostication. A Scientific Statement from the International Liaison Committee on Resuscitation; the American Heart Association Emergency Cardiovascular Care Committee; the Council on Cardiovascular Surgery and Anesthesia; the Council on Cardiopulmonary, Perioperative, and Critical Care; the Council on Clinical Cardiology; the Council on Stroke. Resuscitation 79:350-379

Nurse S, Corbett D (1994) Direct measurement of brain temperature during and after intraischemic hypothermia: correlation with behavioral, physiological, and histological endpoints. J Neurosci 14(12):7726-7734

Ostrowski RP, Colohan ART, Zhang JH (2005) Mechanisms of hyperbaric oxygen-induced neuroprotection in rat model of subarachnoid hemorrhage. J Cereb Blood Flow Metab 25:554-571

Peng Z, Ren P, Kang Z, Du J, Lian Q, Liu Y, Zhang JH, Sun X (2008) Up-regulated HIF- $1 \alpha$ is involved in hypoxic tolerance induced by hyperbaric oxygen preconditioning. Brain Res 1212:71-78

Rink C, Roy S, Khan M, Ananth P, Kuppusamy P, Sen CK, Khanna S (2010) Oxygen-sensitive outcomes and gene expression in acute ischemic stroke. J Cereb Blood Flow Metab 30:1275-1287

Rockswold SB, Rockswold GL, Vargo JM, Erickson CA, Sutton RL, Bergman TA, Biros MH (2001) Effects of hyperbaric oxygenation therapy on cerebral metabolism and intracranial pressure in severely brain injured patients. J Neurosurg 94:403-411

Rockswold SB, Rockswold GL, Zaun DA, Zhang X, Cerra CE, Bergman TA, Liu J (2010) A prospective, randomized clinical trial on compare the effect of hyperbaric to normobaric hyperoxia on cerebral metabolism, intracranial pressure, and oxygen toxicity in severe traumatic brain injury. J Neurosurg 112:1080-1094

Rosenthal RE, Silbergleit R, Hof PR, Haywood Y, Fiskum G (2003) Hyperbaric oxygen reduces neuronal death and improves neurological outcome after canine cardiac arrest. Stroke 34:1311-1316

Sinclair SE, Altemeier WA, Matute-Bello G, Chi EY (2004) Augmented lung injury due to interaction between hyperoxia and mechanical ventilation. Crit Care Med 32:2496-2501

Singhal AB (2006) Oxygen therapy in stroke: past, present, and future. Int J Stroke 1:101-200

Smith G, Lawson DD, Renfrew S, Ledingham IM, Sharp GR (1961) Preservation of cortical activity by breathing oxygen at two atmospheres of pressure during cerebral ischemia. Surg Gynecol Obstet 113:289-292

Sugerman NT, Abella BS (2009) Hospital-based use of therapeutic hypothermia after cardiac arrest in adults. J Neurotrauma 26:371-376

Takahashi M, Iwatsuku N, Ono K, Tajima T, Akama M, Koga Y (1992) Hyperbaric oxygen therapy accelerates neurologic recovery after 15-minute complete global cerebral ischemia in dogs. Crit Care Med 20:1588-1594

Takasu A, Saitoh D, Kaneko N, Sakamoto T, Okada Y (2001) Hyperthermia: is it an ominous sign after cardiac arrest? Resuscitation 49:273-277

Tsai HM, Gao CJ, Li WX, Lin MT, Niu KC (2005) Resuscitation from experimental heatstroke by hyperbaric oxygen therapy. Crit Care Med 33:813-818

Van Hulst RA, Haitsma JJ, Klein J, Lachmann B (2003) Oxygen tension under hyperbaric conditions in healthy pig brain. Clin Physiol Funst Imaging 23:143-148

Van Meter K, Sheps S, Jriedt F, Moises J, Barratt D, Murphy-Lavoie H, Harch PG, Bazan N (2008) Hyperbaric oxygen improves rate of return of spontaneous circulation after prolonged normothermic porcine cardiopulmonary arrest. Resuscitation 78:200-214

Veltkamp R, Siebing DA, Sun L, Heiland S, Biber K, Marti HH, Nagel S, Schwab S, Schwaninger M (2005) Hyperbaric oxygen reduces blood-brain barrier damage and edema after transient focal cerebral ischemia. Stroke 36:1679-1683

Wang X-L, Zhao Y, Yang Y-J, Xie M, Yu X-H (2008) Therapeutic window of hyperbaric oxygen therapy for hypoxic-ischemic brain damage in newborn rats. Brain Res 1222:87-94

Wass CT, Lanier W, Hofer RE, Sheithauer BW, Adnrews AG (1995) Temperature changes of $\geq 1$ degree alter functional neurologic outcome and histopathology in canine model of complete cerebral ischemia. Anesthesiology 83:325-335

Wood SC, Gonzales R (1996) Hypothermia in hypoxic animal: mechanisms, mediators, and functional significance. Comp Biochem Physiol Part B Biochem Mol Biol 113:37-43

Yan W, Zhang H, Bai X, Lu Y, Dong H, Xiong L (2011) Autophagy activation is involved in neuroprotection induced by hyperbaric 
oxygen preconditioning against focal cerebral ischemia in rats. Brain Res 1402:109-121

Yin W, Badr AE, Mychaskiw G, Zhang JH (2002) Down regulation of COX-2 is involved in hyperbaric oxygen treatment in rat transient focal cerebral ischemia model. Brain Res 926:165-171

Yuan Z, Liu W, Liu B, Schnell A, Liu KJ (2010) Normobaric hyperoxia delays and attenuates early nitric oxide production in focal cerebral ischemic rats. Brain Res 1352:248-254

Zaremba J (2004) Hyperthermia in ischemic stroke. Med Sci Monit 10:RA148-RA153
Zhang L, Mitani A, Yanase H, Kataoka K (1997) Continuous monitoring and regulation of brain temperature in the conscious and freely moving ischemic gerbil: effect of MK-801 and delayed neuronal death in hippocampal CA1. J Neurosci Res 47:440-448

Zhang JH, Lo T, Mychaskiw G, Colohan A (2005) Mechanisms of hyperbaric oxygen and neuroprotection in stroke. Pathophysiology 12:65-80

Zhao Q, Memezawa H, Smith ML, Siesjo BK (1994) Hyperthermia complicates middle cerebral artery occlusion induced by intraluminal filament. Brain Res 649:253-259 